\title{
Microbial Vitality of Probiotic Milks Supplemented With Cereal or Pseudocereal Grain Flours
}

\author{
Lisa Maselli ${ }^{1} \&$ Sharareh Hekmat ${ }^{1}$ \\ ${ }^{1}$ Division of Food and Nutritional Sciences, Brescia University College, Western University, London, ON., \\ Canada \\ Correspondence: ShararehHekmat, Division of Food and Nutritional Sciences, Brescia University College, \\ Western University, London, ON, Canada, 1285 Western Road, London, ON., N6G 1H2, Canada. Tel: \\ 1-519-432-8353, ext. 28227. E-mail: hekmat@uwo.ca
}

$\begin{aligned} & \text { Received: September 15, } 2015 \\ & \text { Accepted: September 30, } 2015 \quad \text { Online Published: March 23, } 2016 \\ & \text { doi:10.5539/jfr.v5n2p41 }\end{aligned}$ URL: http://dx.doi.org/10.5539/jfr.v5n2p41

\begin{abstract}
Probiotic products containing Lactobacillus rhamnosus GR-1 have been shown to help decrease the risk of urogenital infections, delay the decline of CD4 lymphocytes in patients with human immunodeficiency virus, and survive in the intestinal tract without stimulating immune or inflammatory responses. Cereal and pseudocereal grains can act as prebiotic agents and could be an economical way of improving the nutritional value, functional qualities, and overall health benefits of probiotic products. The purpose of this study was to measure the growth and survival of L. rhamnosus GR-1 in fermented probiotic skim milk supplemented with a grain flour over a 28-day storage period. The objective was to determine if supplementation of the grain flours would have a positive effect on the microbial vitality of L. rhamnosus GR-1 in the final product and during storage. Five probiotic skim milk samples supplemented with a grain flour were prepared: oat (3\% weight to volume ratio), lentil $(3 \% \mathrm{w} / \mathrm{v})$, rice $(3 \% \mathrm{w} / \mathrm{v})$, barley $(3 \% \mathrm{w} / \mathrm{v})$, and quinoa $(3 \% \mathrm{w} / \mathrm{v})$ along with one control probiotic skim milk sample. Results showed that the oat, rice, barley and quinoa flours supported the growth of $L$. rhamnosus GR-1 at viable levels $\left(10^{8} \mathrm{CFU} / \mathrm{mL}\right)$ during the first 14 days of storage; however, only skim milk supplemented with rice flour sustained the growth over the 28-day storage period. Future studies should conduct a sensory evaluation of this fermented probiotic rice flour milk as well as study rice milk inoculated with probiotics to produce a dairy-free and possible gluten-free product.
\end{abstract}

Keywords: barley, cereal grains, flour, lentil, oat, prebiotics, probiotic milk, quinoa, rice

\section{Introduction}

\subsection{Introduction to Probiotics}

Probiotic bacteria can provide numerous therapeutic effects such as moderating the immune system, lowering blood cholesterol, reducing lactose intolerance, diminishing the effects of Crohn's disease and alleviating diarrhea (Hekmat, Soltania, \& Reid, 2009). Probiotic food products should contain a minimum of $10^{6}-10^{9}$ colony-forming units (CFU) per 100g in order to provide health benefits; however, doses below $10^{8} \mathrm{CFU}$ per day should not be considered effective unless the product proliferates the probiotic effects in the digestive tract (Reid, 2001). The use of the probiotic strain Lactobacillus rhamnosus GR-1 in yogurt has been found to lower the risk of some urogenital infections and yeast infections, and to delay the decline of CD4 lymphocytes in patients with human immunodeficiency virus (HIV) (Anukam, Osazuwa, Osadolor, Bruce, \& Reid, 2008; Hekmat et al., 2009; Hemsworth, Hekmat, \& Reid, 2012; Reid et al., 2003). This strain is bile resistant and can survive passage through the human gastrointestinal tract without stimulating immune or inflammatory responses (Gardiner et al., 2002; Reid, Burton, Hammond, \& Bruce, 2004). When probiotics are incorporated into food products, microbial culture viability tends to decrease (Douglas \& Sanders, 2008).

\subsection{Cereal or Pseudocereal Grains as a Prebiotic}

In contrast, prebiotics are food ingredients such as certain carbohydrates that positively modify the function or growth of probiotic bacteria strains in the intestinal tract (Figueroa-González, Quijano, Ramírez, \& Cruz-Guerrero, 2011). Recent studies have shown interest in using cereal or pseudocereal grains as a prebiotic due to their carbohydrate and nutritional value (Blandino, Al-Aseeri, Pandiella, Cantero, \& Webb, 2003; 
Charalampopoulos, Pandiella, \& Webb, 2003; Espirito-Santo et al., 2014; Gokavi, Zhang, Huang, Zhao, \& Guo, 2005; Helland, Wicklund, \& Narvhus, 2004; Kabeir, Abd-Aziz, Muhammad, Shuhaimi, \& Yazid, 2005; Lazaridou, Serafeimidou, Biliaderis, Moschakis, \& Tzanetakis, 2014; Rosburg, Boylston, \& White, 2010; Saman, Fuciños, Vázquez, \& Pandiella, 2009). The literature shows fermented dairy or cereal-based products such as yogurts, porridges, and gruel, being produced and inoculated with various probiotics to be tested for treating specific diseases, aside from having general health benefits (Agil et al., 2013; Angelov, Gotcheva, Kuncheva, \& Hristozova, 2006; Bianchi, Rossi, Gomes, \& Sivieri, 2015; Casarotti, Carneiro, \& Penna, 2014; Charalampopoulos et al., 2003; Coman et al., 2013; Espirito-Santo et al., 2014; Helland et al., 2004; Kabeir et al., 2005; Kedia, Vázquez, \& Pandiella, 2008; Lazaridou et al., 2014; Luana et al., 2014; Rosburg et al., 2010; Saman et al., 2009; Singh, Kim, \& Liu, 2012). These studies yielded mostly significant results for microbial growth but more research is needed to test other probiotic strains and alternate dairy products such as milk.

\subsection{Grain Flours}

\subsubsection{Oat}

Oats are a source of dietary fiber that have been found to reduce the risk of certain cancers, decrease constipation, lower cholesterol, and control diabetes (Gokavi et al., 2005). Oat bran contains the fiber beta-glucan which contributes to health benefits such as reducing the risk of cardiovascular disease and stroke (Coman et al., 2013; Lazaridou et al., 2014). Beta-glucan has also been found to aid in enhancing the human immune system's response to bacterial infection (Coman et al., 2013). Studies which tested fermented dairy products containing oat flour mainly found that the beta-glucan increased the microbial count of different Lactobacillus probiotic strains (Angelov et al., 2006; Coman et al., 2013; Gokavi et al., 2005; Kedia et al., 2008; Lazaridou et al., 2014; Luana et al., 2014; Singh et al., 2012).

\subsubsection{Rice}

Rice is a source of carbohydrates, protein, iron, calcium, thiamine, riboflavin and niacin (Saman et al., 2009). Bran rice, a particular component of rice, has been shown to maintain normal blood pressure, glycemia, and serum cholesterol levels (Saman et al., 2009). Antioxidants in bran rice may act as a prebiotic that can help control colitis by managing microbial colonies in the digestive tract (Saman et al., 2009). Studies that have tested rice flour in fermented milk-based gruels, porridges, and puddings showed good growth and survival of various Lactobacillus strains such as L. rhamnosus GG (Espirito-Santo et al., 2014; Helland et al., 2004; Kabeir et al., 2005; Saman et al., 2009).

\subsubsection{Lentil}

Lentils contain carbohydrates, proteins, minerals, vitamins, antioxidants, and small amounts of unsaturated fats (Zare, Orsat, Champagne, Simpson, \& Boye, 2012). Associated health benefits include lowering the risk of diabetes, colon cancer, and cardiovascular disease (Agil et al., 2013). Research so far has found that milk supplemented with lentil flour increased the microbial count of yogurt starter cultures and the strain $L$. rhamnosus AD 200, compared to controls (Agil et al., 2013; Zare, Champagne, Simpson, Orsat, \& Boye, 2011; Zare et al., 2012).

\subsubsection{Barley}

Barley is a source of beta-glucan fiber and the health benefits from beta-glucan have been previously described in section 1.3.1. Current research concluded that barley extracts have a positive effect on the viability of various Lactobacillus strains in fermented cereal-based probiotic beverages (Charalampopoulos et al., 2003; Kocková, Dilongová, Hybenová, \& Valík, 2013; Lazaridou et al., 2014; Rathore, Salmerón, \& Pandiella, 2012). Interestingly, Kocková et al. (2013) found that barley flour produced the highest probiotic culture density for $L$. rhamnosus GG when compared to other cereal-grain flours while Vasiljevic, Kealy and Mishra (2007) obtained no measurable effects from barley flour on a Bifidobacterium probiotic strain.

\subsubsection{Quinoa}

Quinoa is classified as a pseudocereal and has a higher protein content compared to many cereal grains while containing all the essential amino acids along with fiber, iron, vitamins, and antioxidants (Bianchi et al., 2015; Casarotti et al., 2014). So far, studies examining quinoa in the form of flour or water extract found no significant effect on probiotic bacteria microbial counts (Bianchi et al., 2015; Casarotti et al., 2014; El-Deeb, Hassan, \& Hassanein, 2014).

\subsection{Importance of Study}

More research is needed in producing food products with grains such as a milk beverage, testing microbial 
vitality for different probiotic strains, as well as testing the overall health benefits from these products. Nutrient content of probiotic beverages will vary due to the type of grains used for supplementation. The growth capacity for each probiotic strain will differ based on the various nutrients in the fermented milk (Gokavi et al., 2005). Thus, it is necessary to study different strains of probiotics to create the most effective and nutritious product in combination with various grains. Research examining the effects on L. rhamnosus GR-1 will be important because there is limited research as of present that has specifically investigated producing probiotic milk products fermented with grains and L. rhamnosus GR-1.

For this study, six probiotic skim milks were developed. Five of the milk samples were supplemented with a different cereal or pseudocereal grain flour, while one milk sample remained as the control. The purpose of this study was to measure the growth and survival of the probiotic L. rhamnosus GR-1 in the fermented, flour-supplemented, skim milks. The objective was to determine if supplementation of the grain flours (oat, white rice, green lentil, barley, and quinoa) would have a positive effect by increasing the microbial vitality of $L$. rhamnosus GR-1 in the final skim milk products and during storage.

\section{Materials and Methods}

\subsection{Probiotic Culture Stock Preparation}

$10 \%$ (weight to volume ratio) of L. rhamnosus GR-1 was inoculated into sterilized de Man, Rogosa and Sharpe (MRS) broth (EMD Chemicals Inc., Gibbstown, NJ) and was incubated anaerobically (BDGasPak ${ }^{\mathrm{TM}}$ EZ Anaerobe Container System, Becton Dickinson \& Co., Sparks, BD), for 24 hours at $37.5^{\circ} \mathrm{C}$. Stocks were prepared on a routine basis in MRS broth.

\subsection{Milk Samples Preparation}

\subsubsection{Skim Milk (Control)}

Skim milk $\left(0.1 \%\right.$ milk fat) $\left(\right.$ Neilson ${ }^{\circledR}$ Trutaste ${ }^{\circledR}$ Microfiltered Skim Milk, Saputo Inc., Montreal, QC) was autoclaved for 15 minutes at $15 \mathrm{psi}$ and then cooled to $37^{\circ} \mathrm{C}$.

\subsubsection{Oat Flour Milk}

Milled oat flour (Oat Flour, Bulk Barn \#690, Aurora, ON) was supplemented into skim milk (0.1\% milk fat) (Neilson ${ }^{\circledR}$ Trutaste ${ }^{\circledR}$ Microfiltered Skim Milk, Saputo Inc., Montreal, QC) at a $3 \%$ weight to volume (w/v) ratio. The sample was autoclaved for 15 minutes at $15 \mathrm{psi}$ and then cooled to $37^{\circ} \mathrm{C}$.

\subsubsection{Rice Flour Milk}

Milled white rice flour (White Rice Flour, Gluten-Free, Bulk Barn \#690, Aurora, ON)was supplemented into skim milk ( $0.1 \%$ milk fat) $\left(\right.$ Neilson ${ }^{\circledR}$ Trutaste ${ }^{\circledR}$ Microfiltered Skim Milk, Saputo Inc., Montreal, QC) at a 3\% $\mathrm{w} / \mathrm{v}$ ratio. The sample was autoclaved for 15 minutes at $15 \mathrm{psi}$ and then cooled to $37^{\circ} \mathrm{C}$.

\subsubsection{Barley Flour Milk}

Stone ground barley flour (Barley Flour, Stone Ground, Bulk Barn \#690, Aurora, ON) was supplemented into skim milk $\left(0.1 \%\right.$ milk fat) $\left(\right.$ Neilson ${ }^{\circledR}$ Trutaste ${ }^{\circledR}$ Microfiltered Skim Milk, Saputo Inc., Montreal, QC)at a 3\% $\mathrm{w} / \mathrm{v}$ ratio. The sample was autoclaved for 15 minutes at $15 \mathrm{psi}$ and then cooled to $37^{\circ} \mathrm{C}$.

\subsubsection{Quinoa Flour Milk}

Quinoa flour (Organic Quinoa Flour, Gluten-Free, Bulk Barn \#690, Aurora, ON) was supplemented into skim milk $\left(0.1 \%\right.$ milk fat) (Neilson ${ }^{\circledR}$ Trutaste ${ }^{\circledR}$ Microfiltered Skim Milk, Saputo Inc., Montreal, QC) at a 3\% w/v ratio. The sample was autoclaved for 15 minutes at 15 psi and then cooled to $37^{\circ} \mathrm{C}$.

\subsubsection{Lentil Flour Milk}

Dried green lentils laird (Cedar Phoenicia ${ }^{\mathrm{TM}}$, Montreal, QC) were ground into a fine flour and sifted for particle consistency. The lentil flour was then supplemented into skim milk $(0.1 \%$ milk fat $)$ (Neilson ${ }^{\circledR}$ Trutaste ${ }^{\circledR}$ Microfiltered Skim Milk, Saputo Inc., Montreal, QC) at a 3\% w/v ratio. The sample was autoclaved for 15 minutes at 15 psi and then cooled to $37^{\circ} \mathrm{C}$.

\subsection{Probiotic Milk Samples Production}

At $37^{\circ} \mathrm{C}$, the skim milks (control, oat, rice, lentil, barley, and quinoa) were inoculated individually with $2 \%$ (w/v ratio) stock solution of L. rhamnosus GR-1 and then anaerobically incubated (BDGasPak ${ }^{\mathrm{TM}} \mathrm{EZ}$ Anaerobe Container System, Becton Dickinson \& Co., Sparks, BD) for 24 hours at $37.5^{\circ} \mathrm{C}$. The probiotic milk samples were then stored at $4^{\circ} \mathrm{C}$ for 28 days. 


\subsection{Enumeration of Probiotic}

Selective MRS agar plates were prepared containing 52.2g/L (5.22\%) MRS broth (EMD Chemicals Inc., Gibbstown, NJ), $15 \mathrm{~g} / \mathrm{L}(1.5 \%)$ agar (EMD Chemicals Inc., Gibbstown, NJ), and $0.015 \mathrm{~g} / \mathrm{L}\left(1.5 \times 10^{-3} \%\right)$ fusidic acid (Enzo Life Sciences Inc., Farmingdale, NY) to enumerate Lactobacillus rhamnosus GR-1. The six milk samples were diluted to factors of $10^{-1}, 10^{-3}, 10^{-5}, 10^{-6}$, and $10^{-7}$ in sterile $0.85 \%$ saline solution on days 1,14 , and 28 of refrigerated storage. For each milk sample, $0.1 \mathrm{~mL}$ of the $10^{-6}$, and $10^{-7}$ dilutions were then plated in duplicates on selective MRS agar plates and anaerobically incubated (BDGasPak ${ }^{\mathrm{TM}}$ EZ Anaerobe Container System, Becton Dickinson \& Co., Sparks, BD) for 48 hours at $37.5^{\circ} \mathrm{C}$. After incubation, viable microbial counts of $L$. rhamnosus GR-1weremeasured by averaging the two duplicate plates for each milk sample. The results were recorded in colony-forming units (CFU) per milliliter. Two replications of the milk samples were produced.

\subsection{Statistical Analysis}

Statistical analyses were conducted using SAS ${ }^{\circledR} 9.4$ Software (SAS Institute Inc., Cary, NC). A one-way repeated measures analysis of variance (ANOVA) and Tukey's tests adjustment $(\mathrm{P}<0.05)$ were used to analyze the numbers of the probiotic bacteria within each milk sample and between milk samples, over time.

\section{Results}

\subsection{Microbial Counts and Stability}

All of the skim milk samples were able to support the survival of the probiotic Lactobacillus rhamnosus GR-1 at viable levels of at least $1 \times 10^{8} \mathrm{CFU} / \mathrm{mL}$ over the 28 -day storage period. Specifically, the samples oat, rice, barley, and quinoa supported an increase in the microbial count by day 14 , but the sample containing rice flour was the only sample that did not significantly decrease in microbial count between days 14 to 28 . Figure 1 illustrates the enumeration of L. rhamnosus GR-1 for all five samples and the control over a 28-day storage period.

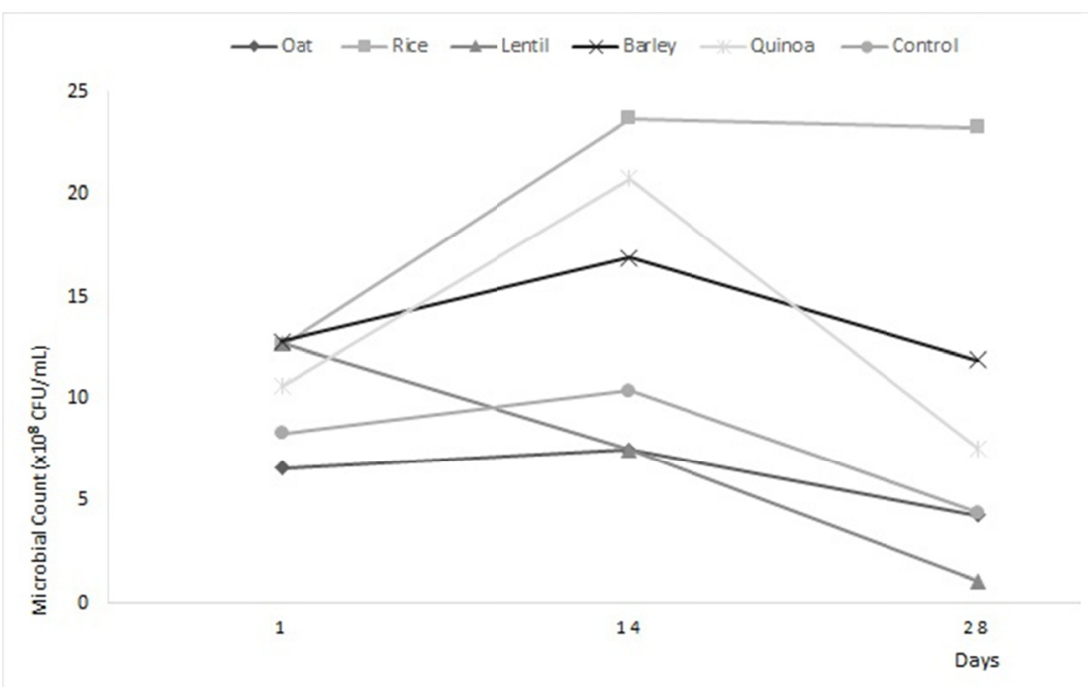

Figure 1. Enumeration (x10 $\left.{ }^{8} \mathrm{CFU} / \mathrm{mL}\right)$ of skim milk samples over time (days)

Note. Mean microbial counts of L. rhamnosus GR-1 in probiotic skim milk samples supplemented with grain flours, and control (probiotic skim milk) over a 28-day storage period. Average of both replications. Where differences occur can be identified using Tukey's test for multiple comparisons.

The initial mean counts $\left(\mathrm{x} 10^{8} \mathrm{CFU} / \mathrm{mL}\right)$ of $L$. rhamnosus GR-1 for oat, rice, lentil, barley, quinoa, and control samples were: $6.6 \pm 0.2,12.6 \pm 3.0,12.7 \pm 2.5,12.8 \pm 3.8,10.6 \pm 7.8$, and $8.3 \pm 3.9$, respectively. Mean microbial counts $\left(\mathrm{x} 10^{8} \mathrm{CFU} / \mathrm{mL}\right)$ on day 14 were: $7.5 \pm 2.2,23.7 \pm 1.8,7.5 \pm 2.5,16.9 \pm 2.9,20.8 \pm 6.5$, and 10.4 \pm 3.2 , for oat, rice, lentil, barley, quinoa, and control samples, respectively. By day 28 , the mean microbial counts $\left(\mathrm{x} 10^{8} \mathrm{CFU} / \mathrm{mL}\right)$ were: $4.3 \pm 3.1,23.3 \pm 4.6,1.1 \pm 0.5,11.9 \pm 3.7,7.6 \pm 2.6$, and $4.4 \pm 3.5$ for oat, rice, lentil, barley, quinoa, and control samples, respectively. The rice flour milk sample was found to have the highest mean count of $23.3 \pm 4.6 \times 10^{8} \mathrm{CFU} / \mathrm{mL}$ at day 28 of storage. Table 1 shows that the rice flour milk was significantly different overall in comparison to the other samples $(\mathrm{p}=0.025)$. The rice flour sample was significantly different between days 1 vs $14(\mathrm{p}=0.029)$ and days 1 vs $28(\mathrm{p}=0.032)$. As seen in Figure 1 , the microbial count for the rice 
flour milk sample plateaued between days 14 to 28 . This result is favorable in comparison to the remaining milk samples which saw a decrease in microbial count between days 14 to 28 . Table 1 shows that the barley flour milk sample was also significantly different overall when compared to other milk samples $(\mathrm{p}=0.017)$. The barley flour milk sample was significantly different between days 1 vs $14(\mathrm{p}=0.026)$ and between days 14 vs $28(\mathrm{p}=0.018)$; however, the microbial count decreased by day 28.The lentil flour milk sample was significantly different in comparison to the other milk samples $(\mathrm{p}=0.019)$ as seen in Table 1 . This is due to the decrease in microbial vitality over time (Figure 1); thus, this result is not favorable.

Table 1. P-Values $(\mathrm{p}<0.05)$ for within samples comparison of days $\left(\times 10^{8} \mathrm{CFU} / \mathrm{mL}\right)$

\begin{tabular}{lllll}
\hline & Overall & Day 1 vs Day 1 & Day 1 vs Day 28 & Day 14 vs Day 28 \\
\hline Oat & 0.343 & & & \\
Rice & $\mathbf{0 . 0 2 5}$ & $\mathbf{0 . 0 2 9}$ & $\mathbf{0 . 0 3 2}$ & 0.947 \\
Lentil & $\mathbf{0 . 0 1 9}$ & $\mathbf{0 . 0 8 2}$ & $\mathbf{0 . 0 1 8}$ & 0.057 \\
Barley & $\mathbf{0 . 0 1 7}$ & $\mathbf{0 . 0 2 6}$ & 0.352 & $\mathbf{0 . 0 1 8}$ \\
Quinoa & 0.072 & & & \\
Control & $\mathbf{0 . 0 0 8}$ & 0.056 & $\mathbf{0 . 0 1 6}$ & $\mathbf{0 . 0 0 7}$ \\
\hline
\end{tabular}

Note. Analysis completed on the average of both milk sample replications. The conventional approach is to not report pairwise comparisons if the overall comparison is not statistically significant. Significant p-values are bolded.

\subsection{Comparison Between Milk Samples}

By day 28 of storage, significant differences in the microbial counts for L. rhamnosus GR-1 were found between the following milk samples (Table 2): rice and control $(\mathrm{p}=0.009)$, rice and oat $(\mathrm{p}=0.010)$, rice and lentil $(\mathrm{p}=0.005)$, and between rice and quinoa $(\mathrm{p}=0.028)$. This suggests that overall, white rice flour has the potential to act as a prebiotic to significantly grow the probiotic L. rhamnosus GR-1 in skim milk and maintain this growth during the storage period.

Table 2. P-Values $(\mathrm{p}<0.05)$ for pairwise comparisons between samples for Day $28\left(\mathrm{x} 10^{8} \mathrm{CFU} / \mathrm{mL}\right)$

\begin{tabular}{llllll}
\hline & Control & Oat & Lentil & Barley & Quinoa \\
\hline Oat & $>0.999$ & & & & \\
Lentil & 0.966 & 0.938 & & & \\
Barley & 0.329 & 0.376 & 0.143 & & \\
Quinoa & 0.796 & 0.852 & 0.428 & 0.900 & \\
Rice & $\mathbf{0 . 0 0 9}$ & $\mathbf{0 . 0 1 0}$ & $\mathbf{0 . 0 0 5}$ & 0.082 & $\mathbf{0 . 0 2 8}$ \\
\hline
\end{tabular}

Note. Analysis completed on the average of both milk sample replications. There are statistically significant differences between the following samples: rice and control, rice and oat, rice and lentil, and between rice and quinoa. Significant p-values are bolded.

\section{Discussion}

The objective was to determine if supplementation of the different grain flours would have a positive effect on the microbial vitality of Lactobacillus rhamnosus GR-1 in the final product and during storage. Although all milk samples were able to maintain the probiotic at levels of at least $1 \times 10^{8} \mathrm{CFU} / \mathrm{mL}$, only the rice flour milk sample significantly sustained growth over 28 days, reaching a microbial count of $2.3 \times 10^{9} \mathrm{CFU} / \mathrm{mL}$. This result is similar to Helland et al. (2004) which found that L. rhamnosus GG exhibited the highest viable cell count in fermented milk-based puddings containing rice flour by growing to over $1 \times 10^{9} \mathrm{CFU} / \mathrm{mL}$ during a 28-day storage period. The growth of various Lactobacillus strains during less than 30 hours of fermentation in rice flour gruel and rice flour broth reached levels between 7.0-10.4 log CFU/mL for Espirito-Santo et al. (2014), and Saman et al. (2009), respectively. Kabeir et al. (2005) found significant growth of a Bifidobacterium strain in fermented 
porridge made of rice flour and skim milk, reaching a count of $9.9 \log \mathrm{CFU} / \mathrm{mL}$, and decreasing by $0.9 \log$ $\mathrm{CFU} / \mathrm{mL}$ during a two-week storage period (Kabeir et al., 2005). These studies, including our own, demonstrate that rice flour allows significant probiotic growth; however, it is difficult to compare due to various time frames and probiotic strains.

Studies testing fermented products containing oat flour or flakes found significant results with strains of Lactobacillus plantarum and $L$. paracase $i$ which were found to remain at levels of at least $1 \times 10^{6} \mathrm{CFU} / \mathrm{mL}$ over a 28-day storage period in fermented yogurt or water-based oat beverages (Angelov et al., 2006; Coman et al., 2013; Gokavi et al., 2005; Kedia et al., 2008; Lazaridou et al., 2014; Luana et al., 2014). While L. rhamnosus GR-1 remained above $1 \times 10^{8} \mathrm{CFU} / \mathrm{mL}$ in our oat flour sample, significant microbial growth was not observed. Some studies suggest that beta-glucan found in oat flour protects probiotic strains which may explain why the probiotic remained at a viable level (Coman et al., 2013; Lazaridou et al., 2014; Rosburg et al., 2010).

Milk supplemented with lentil flour increased the microbial count of L. rhamnosus AD 200 to over $1 \times 10^{8} \mathrm{CFU} / \mathrm{mL}$ over a 28-day storage period (Agil et al., 2013; Zare et al., 2011, 2012). The results of Zare et al. (2011, 2012) contradicts our study in which the lentil flour probiotic milk significantly decreased over time; however, the lentil milk in our study was at a level of $1.1 \times 10^{8} \mathrm{CFU} / \mathrm{mL}$ by the end of the storage period. This difference could possibly be due to a difference in the type of lentil flour used or the alternate probiotic strain.

Barley flour was found to have a positive effect on the microbial viability of Lactobacillus plantarum and $L$. acidophilus strains in fermented cereal-based probiotic beverages (Charalampopoulos et al., 2003; Kocková et al., 2013; Rathore et al., 2012). Our results are similar to Kocková et al. (2013) which found that barley flour fermented in water produced the highest probiotic culture density for L. rhamnosus GG when compared to other cereal-grain flours.

Growth of various Bifidobacterium and Lactobacillus strains in fermented milk with quinoa flour or aqueous extracts of quinoa, respectively, were not found to be significant in past studies (Bianchi et al., 2015; Casarotti et al., 2014). Quinoa did not affect microbial growth or provide protective benefits over a 28-day period (Bianchi et al., 2015; Casarotti et al., 2014) while El-Deeb et al. (2014) found that the probiotic bacteria slightly decreased in count after seven days. These results coincide with our study which saw a decrease in the microbial vitality after 14 days.

\section{Conclusion}

Skim milk supplemented with white rice flour supports the growth and survival of L. rhamnosus GR-1 beyond $10^{8} \mathrm{CFU} / \mathrm{mL}$ over a 28 -day storage period to provide health benefits. This study exhibits the potential for production of this fermented probiotic milk product as an alternate food product to deliver the health benefits of probiotics to consumers. Further studies should conduct sensory evaluations, test alternate probiotic strains, and study the microbial vitality of probiotics inoculated in rice milk.

\section{Implications, Limitations, and Future Proposals}

The intention was to create a novel food product that can benefit the general population, but more specifically, individuals seeking relief from yeast infections or urogenital discomfort, as well as to help strengthen the immune system of patients with HIV/AIDS. The possible health benefits of the specific grain flours may also make the fermented probiotic milk products of interest to consumers with or at risk of certain diseases or nutritional deficiencies. The consumption of probiotic yogurt has increased significantly over the past few years in North America (Granato, Branco, Nazzaro, Cruz, \& Faria, 2010; Hekmat et al., 2009). The possibility of a probiotic milk beverage may attract industry and consumer interest as an alternate product for consumption. This study showed that the addition of a grain flour, particularly white rice flour, acted as a prebiotic to increase the microbial vitality of $L$. rhamnosus GR-1. This would ensure a product that offers a viable number of probiotics at consumption, even once the product reaches the end of its shelf life. Besides the known therapeutic effects of the specific probiotic strain, the grain flour may contribute additional health benefits to the product; thus, further research should be conducted to determine this.

A limitation of this study was that the amount of each grain flour (3\% w/v ratio) and the probiotic culture (2\% $\mathrm{w} / \mathrm{v}$ ratio) to be supplemented and inoculated, respectively, were estimated based off of previous studies which were similar but used alternate probiotics, grain flours, and fermented food products (yogurt, gruels etc.). These amounts may not have achieved the best possible results for microbial vitality. Another limitation was that only two replications were conducted. Although the results were similar for each replication, further replications can account for any possible errors during the procedure of the experiment as well as demonstrate if the results remain consistent. 
Future studies with animal models and human clinical trials are necessary to determine any health-related properties of these probiotic, grain-supplemented milks; specifically the rice flour supplemented probiotic milk. Sensory panels with humans should also be conducted using this fermented probiotic rice flour milk to determine consumer acceptance and production of this product at the industry level. Further studies should test the microbial vitality of $L$. rhamnosus GR-1 in rice milk to obtain a lactose-free and possible gluten-free beverage as well as test the microbial vitality of other probiotic strains.

\section{Acknowledgments}

The authors acknowledge and thank Brescia University College at the University of Western Ontario for providing use of the food science laboratory and the laboratory equipment necessary for this study.

\section{References}

Agil, R., Gaget, A., Gliwa, J., Avis, T. J., Willmore, W. G., \& Hosseinian, F. (2013). Lentils Enhance Probiotic Growth in Yogurt and Provide Added Benefit of Antioxidant Protection. LWT - Food Science and Technology, 50(1), 45-49. http://dx.doi.org/10.1016/j.lwt.2012.07.032

Angelov, A., Gotcheva, V., Kuncheva, R., \& Hristozova, T. (2006). Development of a New Oat-based Probiotic $\begin{array}{lllll}\text { Drink. International Journal of Food Microbiology, } & \text { 112(1), }\end{array}$ http://dx.doi.org/10.1016/j.ijfoodmicro.2006.05.015

Anukam, K. C., Osazuwa, E. O., Osadolor, H. B., Bruce, A. W., \& Reid, G. (2008). Yogurt Containing Probiotic Lactobacillus Rhamnosus GR-1 and L. Reuteri RC-14 Helps Resolve Moderate Diarrhea and Increases CD4 Count In HIV/AIDS Patients. Journal of Clinical Gastroenterology, 42(3), 239-43. http://dx.doi.org/10.1097/MCG.0b013e31802c7465

Bianchi, F., Rossi, E., Gomes, R., \& Sivieri, K. (2015). Potentially Synbiotic Fermented Beverage with Aqueous Extracts of Quinoa (Chenopodium Quinoa Willd) and Soy. Journal of Food Science and Technology International, 21(6), 403-415.http://dx.doi.org/10.1177/1082013214540672

Blandino, A., Al-Aseeri, M. E., Pandiella, S. S., Cantero, D., \& Webb, C. (2003). Cereal-based Fermented Foods and Beverages. Food Research International, 36(6), 527-543. http://dx.doi.org/10.1016/S0963-9969(03)00009-7

Casarotti, S. N., Carneiro, B. M., \& Penna, A. L. B. (2014). Evaluation of the Effect of Supplementing Fermented Milk with Quinoa Flour on Probiotic Activity. Journal of Dairy Science, 97(10), 6027-6035. http://dx.doi.org/10.3168/jds.2014-8197

Charalampopoulos, D., Pandiella, S. S., \& Webb, C. (2003). Evaluation of the Effect of Malt, Wheat and Barley Extracts on the Viability of Potentially Probiotic Lactic Acid Bacteria Under Acidic Conditions. International Journal of Food Microbiology, 82(2), 133-141. http://dx.doi.org/10.1016/S0168-1605(02)00248-9

Coman, M. M., Verdenelli, M. C., Cecchini, C., Silvi, S., Vasile, A., Bahrim, G. E., ... Cresci, A. (2013). Effect of Buckwheat Flour and Oat Bran on Growth and Cell Viability of the Probiotic Strains Lactobacillus Rhamnosus IMC 501®, Lactobacillus Paracasei IMC 502® and Their Combination SYNBIO ${ }^{\circledR}$, in Synbiotic Fermented Milk. International Journal of Food Microbiology, 167(2), 261-268. http://dx.doi.org/10.1016/j.ijfoodmicro.2013.09.015

Douglas, L. C., \& Sanders, M. E. (2008). Probiotics and Prebiotics in Dietetics Practice. Journal of the American Dietetic Association, 108(3), 510-521. http://dx.doi.org/10.1016/j.jada.2007.12.009

El-Deeb, A. M., Hassan, N. Y., \& Hassanein, A. M. (2014). Preparation and Properties of Flavored Fermented Beverage Based on Partial or Complete Replacement of Milk with Quinoa Seeds Water Extract (QSWE). International Journal of Dairy Science, 9(4), 96-105. http://dx.doi.org/10.3923/ijds.2014.96.105

Espirito-Santo, A. P., Mouquet-Rivier, C., Humblot, C., Cazevieille, C., Icard-Vernière, C., Soccol, C. R., \& Guyot, J. (2014). Influence of Cofermentation by Amylolytic Lactobacillus Strains and Probiotic Bacteria on the Fermentation Process, Viscosity and Microstructure of Gruels Made of Rice, Soy Milk and Passion Fruit Fiber. Food Research International, 57(March 2014), 104-113. http://dx.doi.org/10.1016/j.foodres.2014.01.028

Figueroa-González, I., Quijano, G., Ramírez, G., \& Cruz-Guerrero, A. (2011). Probiotics and Prebiotics-Perspectives and Challenges. Journal of the Science of Food and Agriculture, 91(8), 1341-1348. http://dx.doi.org/10.1002/jsfa.4367

Gardiner, G., Heinemann, C., Baroja, M. L., Bruce, A. W., Beuerman, D., \& Madrena, J. (2002). Oral 
Administration of the Probiotic Combination Lactobacillus Rhamnosus GR-1 and L. Fermentum RC-14 for Human Intestinal Applications. International Dairy Journal, 12(2), 191-196. http://dx.doi.org/10.1016/S0958-6946(01)00138-8

Gokavi, S., Zhang, L., Huang, M., Zhao, X., \& Guo, M. (2005). Oat-based Symbiotic Beverage Fermented by Lactobacillus Plantarum, Lactobacillus Paracasei Ssp. Casei, and Lactobacillus Acidophilus. Journal of Food Science, 70(4), M216-M223. http://dx.doi.org/10.1111/j.1365-2621.2005.tb07191.x

Granato, D., Branco, G. F., Nazzaro, F., Cruz, A. G., \& Faria, J. A. F. (2010). Functional Foods and Nondairy Probiotic Food Development: Trends, Concepts, and Products. Comprehensive Reviews in Food Science and Food Safety, 9(3), 292-302. http://dx.doi.org/10.1111/j.1541-4337.2010.00120.x

Hekmat, S., Soltania, H., \& Reid, G. (2009). Growth and Survival of Lactobacillus Reuteri RC-14 and Lactobacillus Rhamnosus GR-1 in Yogurt For Use As A Functional Food. Innovative Food Science and Emerging Technologies, 10(2), 293-296. http://dx.doi.org/10.1016/j.ifset.2008.10.007

Helland, M. H., Wicklund, T., \& Narvhus, J. A. (2004). Growth and Metabolism of Selected Strains of Probiotic Bacteria in Milk- and Water-Based Cereal Puddings. International Dairy Journal, 14(11), 957-965. http://dx.doi.org/10.1016/j.idairyj.2004.03.008

Hemsworth, J., Hekmat, S., \& Reid, G. (2012). Micronutrient Supplemented Probiotic Yogurt For HIV-Infected Adults Taking HAART In London, Canada. Gut Microbes, 3(5), 414-419. http://dx.doi.org/10.4161/gmic.21248

Kabeir, B. M., Abd-Aziz, S., Muhammad, K., Shuhaimi, M., \& Yazid, A. M. (2005). Growth of Bifidobacterium Longum BB536 in Medida (Fermented Cereal Porridge) and their Survival during Refrigerated Storage. Letters in Applied Microbiology, 41(2), 125-131. http://dx.doi.org/10.1111/j.1472-765X.2005.01735.x

Kedia, G., Vázquez, J. A., \&Pandiella, S. S. (2008). Fermentability of Whole Oat Flour, Peritec Flour and Bran by Lactobacillus Plantarum. Journal of Food Engineering, 89(2), 246-249. http://dx.doi.org/10.1016/j.jfoodeng.2008.04.020

Kocková, M., Dilongová, M., Hybenová, E., \& Valík, L. (2013). Evaluation of Cereals and Pseudocereals Suitability for the Development of New Probiotic Foods. Journal of Chemistry, 2013(414303), 1-8. http://dx.doi.org/10.1155/2013/414303

Lazaridou, A., Serafeimidou, A., Biliaderis, C. G., Moschakis, T., \& Tzanetakis, N. (2014). Structure Development and Acidification Kinetics in Fermented Milk Containing Oat B-Glucan, a Yogurt Culture and a Probiotic Strain. Food $\quad$ Hydrocolloids, 2014), 214. http://dx.doi.org/10.1016/j.foodhyd.2014.01.015

Luana, N., Rossana, C., Curiel, J. A., Kaisa, P., Marco, G., \& Rizzello, C. G. (2014). Manufacture and Characterization of a Yogurt-Like Beverage Made with Oat Flakes Fermented by Selected Lactic Acid Bacteria. International Journal of Food Microbiology, 185(August 2014), 17-26. http://dx.doi.org/10.1016/j.ijfoodmicro.2014.05.004

Rathore, S., Salmerón, I., \& Pandiella, S. S. (2012). Production of Potentially Probiotic Beverages Using Single and Mixed Cereal Substrates Fermented with Lactic Acid Bacteria Cultures. Food Microbiology, 30(1), 239-244. http://dx.doi.org/10.1016/j.fm.2011.09.001

Reid, G. (2001). Regulatory and clinical aspects of dairy probiotics [online]. Background paper for the Joint FAO/WHO Expert Consultation on Evaluation of Health and Nutritional Properties of Probiotics in Food Including Powder Milk with Live Lactic Acid Bacteria. Retrieved from Food and Agriculture Organization of the United Nations (FAO) website: ftp://ftp.fao.org/es/esn/food/Reid.pdf

Reid, G., Burton, J., Hammond, J. A., \& Bruce, A. W. (2004). Nucleic Acid Based Diagnosis of Bacterial Vaginosis and Improved Management Using Probiotic Lactobacilli. Journal of Medicinal Food, 7(2), 223-228. http://dx.doi.org/10.1089/1096620041224166

Reid, G., Charbonneau, D., Erb, J., Kochanowski, B., Beuerman, D., \& Poehner, R. (2003). Oral Use of L. Rhamnosus GR-1 and L. Fermentum RC-14 Significantly Alters Vaginal Flora: Randomized, Placebo-Controlled Trial. FEMS Immunology and Medical Microbiology, 35(2), 131-134. http://dx.doi.org/10.1016/S0928-8244(02)00465-0

Rosburg, V., Boylston, T., \& White, P. (2010). Viability of Bifidobacteria Strains in Yogurt With Added Oat Beta-Glucan and Corn Starch During Cold Storage. Journal of Food Science, 75(5), C439-444. 
http://dx.doi.org/10.1111/j.1750-3841.2010.01620.x

Saman, P., Fuciños, P., Vázquez, J. A., \& Pandiella, S. S. (2009). Fermentability of Brown Rice and Rice Bran For Growth Of Human Lactobacillus Plantarum NCIMB 8826. Food Technology and Biotechnology, 49(1), 128-132. Retrieved from http://www.ftb.com.hr/index.php/archives/58-volume-49-issue-no-1/118

Singh, M., Kim, S., \& Liu, S. X. (2012). Effect of Purified Oat B-Glucan on Fermentation of Set-style Yogurt Mix. Journal of Food Science, 77(8), E195-E201. http://dx.doi.org/10.1111/j.1750-3841.2012.02828.x

Vasiljevic, T., Kealy, T., \& Mishra, V. K. (2007). Effects of $\beta$-Glucan Addition to a Probiotic Containing Yogurt. Journal of Food Science, 72(7), c405-c411. http://dx.doi.org/10.1111/J.1750-3841.2007.00454.X

Zare, F., Champagne, C. P., Simpson, B. K., Orsat, V., \&Boye, J. I. (2011). Effect of the Addition of Pulse Ingredients to Milk on Acid Production by Probiotic and Yoghurt Starter Cultures. LWT - Journal of Food Science and Technology, 45(2), 155-160. http://dx.doi.org/10.1016/j.lwt.2011.08.012

Zare, F., Orsat, V., Champagne, C. P., Simpson, B. K., \& Boye, J. I. (2012). Microbial and Physical Properties of Probiotic Fermented Milk Supplemented with Lentil Flour. Journal of Food Research, 1(1), 94-109. http://dx.doi.org/10.5539/jfr.v1n1p94

\section{Copyrights}

Copyright for this article is retained by the author(s), with first publication rights granted to the journal.

This is an open-access article distributed under the terms and conditions of the Creative Commons Attribution license (http://creativecommons.org/licenses/by/3.0/). 